\title{
Riscos ocupacionais em catadores de materiais recicláveis (Campina Grande, Estado da Paraíba, Nordeste do Brasil)
}

\section{Fábio Giovanni de Araújo Batista}

Faculdade de Ciências Médicas. Av. Sen. Argemiro de Figueiredo, 1901. Sandra Cavalcante. Campina Grande-PB, Brasil (CEP 58411-020). E-mail: fabiogiovanni77@gmail.com.

Resumo. A gestão dos resíduos sólidos urbanos municipais compõe fator importante para com a responsabilidade socioambiental em detrimento da sustentabilidade local. 0 catador de resíduos sólidos constitui importante personagem por agregar valor aos descartes sociais, segregando e acondicionando em condições de venda. As tarefas executadas no galpão da Associação dos Catadores de Materiais Recicláveis da Comunidade Nossa Senhora Aparecida (ARENSA), localizado no Município de Campina Grande, Estado da Paraíba, Nordeste do Brasil, por trabalhadores associados, delinearam este artigo, por propiciar a caracterização e classificação de riscos ocupacionais que eles estão susceptíveis. Os objetivos deste artigo foram a observação dos métodos de trabalho, a caracterização dos materiais de interesse, a avaliação dos riscos físicos, químicos e biológicos inerentes ao trabalho, bem como a elaboração de matriz de riscos. Foram observados 16 diferentes materiais, seguindo-se a nomenclatura adotada pelos catadores. Os riscos físicos foram identificados em papel branco, plástico grade, PEAD, PVC, alumínios fino e duro, vidros, ferragens e na extração da bobina de cobre, os riscos químicos foram observados nos plásticos PEAD, bacias e vidros, os riscos biológicos foram constatados em 15 dos produtos com exceção da bobina de cobre. Após avaliação dos riscos ocupacionais, via matriz de riscos e padrão para Riscos Ocupacionais à Saúde e Segurança (ROSS) foi possível classificá-los em leves (43,75\%), moderados $(43,75 \%)$ e críticos $(12,5 \%)$, estando todos acima dos padrões estimados.

Palavras-chave: Riscos ocupacionais; Saúde; Segurança do trabalho; Resíduos sólidos.

Abstract. Occupational risks in recyclable material collectors (Campina Grande, Paraíba State, Northeast Brazil). The management of municipal solid waste is an important factor for social and environmental responsibility at the expense of local sustainability. The solid waste collector is an important character for adding value to social waste, segregating and conditioning it into conditions of sale. The tasks performed in the Associação dos Catadores de Materiais Recicláveis da Comunidade Nossa
Recebido:

28/05/2019

Aceito:

25/08/2019

Disponível on line:

26/08/2019

Publicado:

31/08/2019

Acesso aberto

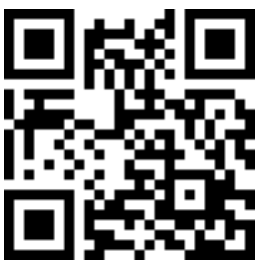

ORCID

(ㄱ) 0000-0003-4468-6481 Fábio Giovanni de Araújo Batista 
Senhora Aparecida (ARENSA) warehouse, located in the Municipality of Campina Grande, Paraíba State, Northeast Brazil, by associated workers, outlined this article, by providing the characterization and classification of occupational risks that they are susceptible. The objectives of this article were the observation of the working methods, the characterization of the materials of interest, the evaluation of the physical, chemical and biological risks inherent to the work, as well as the elaboration of a risk matrix. Sixteen different materials were observed, following the nomenclature adopted by the pickers. Physical hazards were identified on white paper, grid plastic, HDPE, PVC, fine and hard aluminum, glass, hardware and copper coil extraction, chemical hazards were observed on HDPE plastics, basins and glass, biological hazards were found in 15 of the products except the copper coil. After assessing occupational risks, through the risk matrix and standard for Occupational Health and Safety Risks (ROSS), it was possible to classify them as mild (43.75\%), moderate (43.75\%) and critical $(12.5 \%)$, all of which are above the estimated standards.

Keywords: Occupational risks; Health; Work safety; Solid waste.

\section{Introdução}

Os resíduos sólidos representam o mais notório produto da sociedade moderna. A partir da exacerbada produção, faz-se possível descrever o grau de consumo e perfil socioeconômico decorrentes de um modelo itinerante e acelerado de desenvolvimento econômico e social. Os descartes tornaram-se, mediante a evolução das populações, cada vez mais preocupantes e diversos, dentre eles, pode-se encontrar desde os resíduos orgânicos a chips de computador e aparelhos de telefonia móvel.

Provenientes das atividades industrial, doméstica, comercial, agrícola e de serviços, os resíduos sólidos devem ter gestão bem elaborada, adequada e participativa em preocupação com os possíveis e sérios danos que podem acometer ao ambiente e a sociedade (Andrade e Ferreira, 2012).

As questões de ordem ambiental e para a gestão dos resíduos sólidos urbanos, foram motivadores definitivos para a instituição do Decreto $\mathrm{n}^{\mathrm{o}}$ $7.404 / 2010$, que regulamentou a Lei $\mathrm{n}^{\mathrm{o}}$
12.305/2010, e criação do Comitê Interministerial da Política Nacional dos Resíduos Sólidos (PNRS) e o Comitê Orientador para a implantação dos Sistemas de Logística Reversa (Lei $\mathrm{n}$ $7.802 / 1989$, regulamentada pelo Decreto no 4.074/2002), que inovou ao contemplar a responsabilidade compartilhada pelo ciclo de vida dos produtos, visto o gerenciamento dos resíduos sólidos não apenas ter nos gestores públicos o responsável majoritário, mas também, a esta competir aos fabricantes, importadores, distribuidores, comerciantes e consumidores. A mesma também determina o caráter de diretrizes, a eliminação de lixões e disposição final, ambientalmente adequada de rejeitos, recuperação de lixões e aterros controlados e a criação de um índice nacional de avaliação da qualidade dos aterros sanitários (Brasil, 2010; Vieira et al., 2012).

O catador de materiais recicláveis é caracterizado como um ator socioambiental que, remexendo o "lixo" da sociedade, segrega o que é de fato descartável de materiais com condições 
para geração de renda. Apesar dos aspectos negativos que a função da catação apresenta em seu mais representativo conceito (risco de doenças, más condições de trabalho, discriminação social), o trabalhador se faz personagem importante questões de ordem pública sanitária, com ação efetiva nos setores ambiental, social e econômico. Sabe-se que os municípios brasileiros, geralmente, têm enormes dificuldades quanto a áreas que sirvam como local de disposição dos resíduos sólidos e por isso, quanto menos resíduos forem confinados, menor será o impacto à ambiência e à sociedade como um todo (Jacobi, 2003).

A existência de impactos negativos à saúde e à qualidade de vida dos trabalhadores catadores de materiais recicláveis é expressiva e relevante como questão de ordem pública e social, devido ao modo de inserção no campo de trabalho, sem que existam equipamentos adequados para reduzir ou impedir o contato direto com produtos contaminados ou que ofereçam risco à integridade física.

0 trabalho executado pelos catadores de materiais recicláveis requer atenção quanto às condições do exercício e a heterogeneidade dos materiais de interesse ao processamento adequado para comercialização, compostos das etapas de triagem e acondicionamento, os quais podem ser reveladores das condições de trabalho quanto ao grau de periculosidade ofertada e inerentes aos mesmos.

Abordagem sobre os riscos ocupacionais em associação de catadores de materiais recicláveis da cidade de Campina Grande, Paraíba, compõe pesquisa por variáveis de cunho interdisciplinar, visto a utilização de materiais de descarte configurados como passivos e agressores ambientais, a inserção dos trabalhadores como agentes socioambientais, juntamente com os desafios e conquistas para consolidação do grupo de trabalho e os riscos à saúde e segurança vivenciados devido os tipos de resíduos sólidos e as diferentes técnicas empregadas para o trabalho de triagem e acondicionamento, evidenciando o reconhecimento e a utilização de ferramentas e equipamentos de proteção individual, sejam para maximizar a operação e conferir redução dos acidentes de trabalho.

\section{Metodologia}

O cenário para experimentação da pesquisa foi constituído pelo galpão de triagem da Associação dos Catadores de Materiais Recicláveis da Comunidade Nossa Senhora Aparecida (ARENSA). 0 galpão está localizado no Bairro do Tambor, na Rua Manoel Alves de Oliveira, em Campina Grande, Paraíba. Tem localização global de latitude $-7^{\circ} 15^{\prime}$ 2.649" S e longitude $-35^{\circ} 53^{\prime} 8,3394^{\prime \prime} \mathrm{W}$ (Figura 1) e constituiu ambiente para verificação e levantamento das análises dos riscos ocupacionais, que integra seis trabalhadores associados, os quais realizam triagem, segregação e acondicionamento dos resíduos sólidos coletados para posterior comercialização.

A periodicidade do levantamento de dados foi condizente ao acompanhamento da rotina de trabalho dos catadores de materiais recicláveis da ARENSA, tendo sido realizada no quadrimestre que compreendeu os meses de março a junho de 2013, ocorrendo em dois dias por semana, quintas e sextas-feiras, sendo observadas as atividades executadas no intervalo das 14:00 $\mathrm{h}$ às 17:00 $\mathrm{h}$, intervalo em que os catadores destinam para a triagem e segregação dos materiais coletados durante o período matutino.

\section{Qualificação dos resíduos sólidos urbanos}

A qualificação dos materiais de interesse pelos trabalhadores da ARENSA, triados e acondicionados no galpão, que por se destinarem à comercialização, são compostos em maior percentual por resíduos secos, 
obedeceram aos padrões estimados pela norma ABNT NBR no 10.004:2004 (ABNT, 2004) e Resolução CONAMA no 358/2005 (Brasil, 2005), como requisitos para preenchimento de matriz para avaliação de riscos, o qual expõe os diferentes riscos existentes para os tipos de materiais recicláveis.
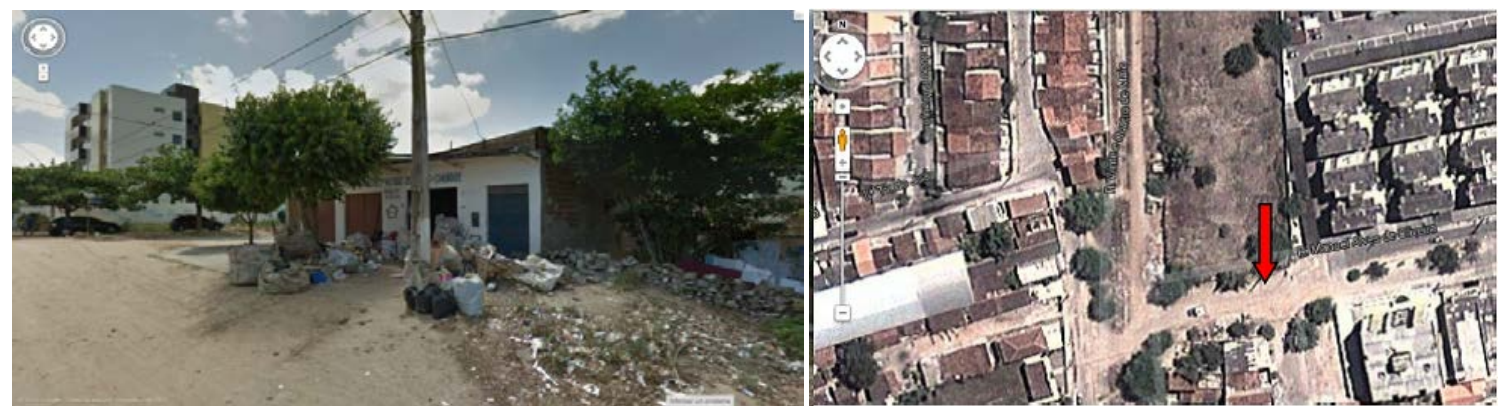

Figura 1. Visualização do galpão de triagem da ARENSA em vista frontal (à esquerda) e visualização de satélite (à direita) indicado por seta vermelha.

\section{Qualificação dos resíduos sólidos urbanos}

A qualificação dos materiais de interesse pelos trabalhadores $\mathrm{da}$ ARENSA, triados e acondicionados no galpão, que por se destinarem à comercialização, são compostos em maior percentual por resíduos secos, obedeceram aos padrões estimados pela norma ABNT NBR no 10.004:2004 (ABNT, 2004) e Resolução CONAMA no 358/2005 (Brasil, 2005), como requisitos para preenchimento de matriz para avaliação de riscos, o qual expõe os diferentes riscos existentes para os tipos de materiais recicláveis.

Foram consideradas as formas e mecanismos de segregação determinadas e realizadas pelos membros da associação para classificação dos RSU, não sendo objetivo inserir metodologia de caracterização ao trabalho já realizado. 0 levantamento seguiu escala qualitativa, compondo os resultados a partir dos padrões estabelecidos pelos trabalhadores, sejam para os tipos de plásticos, metais, vidros, papéis, papelões, descartados eletrônicos, entre outros identificados. A segregação e caracterização dos resíduos sólidos coletados permitem um aproveitamento racional e estruturado e reduz ainda mais o dispêndio de recursos na identificação, seleção e acondicionamento dos resíduos.

Previamente listados e caracterizados, os RSU de interesse à venda, reaproveitamento e reciclagem, compõem o grupo inicial de variáveis constituintes da matriz de risco.

\section{Avaliação de riscos em resíduos sólidos urbanos \\ Para determinação dos riscos} físicos, os resíduos identificados foram caracterizados em cortante ou perfurante, para melhor arranjo de grupo de dados. A análise foi realizada mediante acompanhamento da rotina de trabalho no galpão de triagem, na segregação e/ou acondicionamento dos materiais recolhidos, estimando-se a percepção inicial do catador de materiais recicláveis que manuseia diretamente os resíduos, seja com ou sem EPI's. Foram observadas as práticas de desmanche, como é o caso das bobinas de motores elétricos para o beneficiamento dos fios de cobre, como atividade exercida para o beneficiamento de subproduto.

A definição dos riscos químicos oriundos dos RSU procedeu por 
observação direta de resíduos que emitiam odor desagradável característico, com consequente geração de náuseas, cefaleias, ânsias de vômito, tonturas ou qualquer outra sintomatologia que evidenciassem contaminação por constituintes químicos, previamente relatados estes pelos catadores. Foram definidos grupos de riscos quanto à contaminação via contato dérmico, ocular e olfativo. A identificação predita propicia relacionar determinado resíduo, não devidamente higienizado ou comprometido, com os possíveis riscos que pode vir a causar segundo o fabricante e as normas de exposição a resíduos químicos indicados pela Resolução CONAMA no 358/2005 (Brasil, 2005).

Os riscos biológicos foram caracterizados por análises de amostras devidamente preparadas a partir dos RSU, para avaliação colimétrica. Essa análise objetivou a avaliação dos Coliformes Termotolerantes, que segunda a Resolução CONAMA $\mathrm{n}$ 357/2005 (Brasil, 2005), são representados por bactérias gramnegativas, em forma de bacilos.

A indicação de coliformes Termotolerantes nos resíduos de pesquisa indica a contaminação dos mesmos por poluentes de origem sanitária enfatizando a preocupação de cuidados adequados, devido aos riscos de contaminação por patógenos microbianos de veiculação hídrica.

A preparação de amostras para análises constou da composição de um substrato líquido derivado da lavagem de dez materiais para cada grupo de resíduos sólidos urbanos, na região externa, visto constituir área de contato dos catadores de materiais recicláveis, devido a não utilização de luvas no processo de triagem e acondicionamento.

A devida identificação dos materiais de interesse à venda pelos associados da ARENSA remeteu à classificação dos mesmos segundo padrões da norma ABNT NBR 10004/2004 (ABNT, 2004) e Resolução CONAMA no 358/2005 (Brasil, 2005), sendo a primeira norma determinadora do grau de periculosidade dos materiais e o posterior padrão dispõe sobre os resíduos e a saúde.

\section{Matriz de riscos ocupacionais}

Os riscos ocupacionais devem considerar padrões internacionais, previamente estabelecidos pela norma OHSAS 18001 (Occupational Health and Safety Assessment Series) desenvolvida em 1996, por um grupo de organismos certificadores (BSI, BVQI, DNV, Lloyds Register, SGS, entre outros) com aval de entidades nacionais de normalização da Irlanda, Austrália, África do Sul, Espanha e Malásia, de cunho qualitativo. Esta é considerada primordial norma de certificação para sistemas de gestão de saúde e segurança ocupacional de alcance global, publicada oficialmente pela BSI (1999) e entrou oficialmente em vigor em 15/04/1999 (Cicco, 2009). A mesma estabelece sistema para gestão de saúde e segurança ocupacional, a qual propõe processo de gestão de segurança e saúde na ocupação que visa reduzir ou eliminar completamente os riscos aos trabalhadores e outras partes interessadas, pertencentes à organização que possam estar expostos a determinados riscos na rotina das atividades.

De acordo com proposições de elaboração para matriz de risco, indicadas por Torres e Gama (2005), pode-se considerar como variáveis de controle e acompanhamento para os RSU, os critérios de significância adotados e suas escalas de valores para o preenchimento, de acordo com a Tabela 1. 
Tabela 1. Critérios de avaliação com escala de valores numéricos para a significância do risco à segurança e saúde ocupacional.

\begin{tabular}{|c|c|c|c|c|c|c|c|}
\hline \multicolumn{2}{|c|}{ Frequência } & \multicolumn{2}{|c|}{$\begin{array}{c}\text { Escala que afeta os } \\
\text { catadores de } \\
\text { materiais recicláveis }\end{array}$} & \multicolumn{2}{|c|}{$\begin{array}{c}\text { Exposição } \\
\text { considerando a } \\
\text { jornada de trabalho }\end{array}$} & \multicolumn{2}{|r|}{ Gravidade } \\
\hline 1 & Possível & 1 & $<30 \%$ & 1 & $<25 \%$ & 1 & Lesões leves \\
\hline 2 & Pouco Provável & 3 & $30 \% \geq 70 \%$ & 3 & $25 \% \geq 75 \%$ & 3 & Lesões Moderadas \\
\hline 3 & Provável & & & & & & \\
\hline 4 & Muito Provável & 5 & $\geq 70 \%$ & 5 & $\geq 75 \%$ & 5 & Lesões Graves \\
\hline
\end{tabular}
Para relação de significância, equacionamento de variáveis, proposto deve-se considerar a seguinte por Cerqueira (2006):

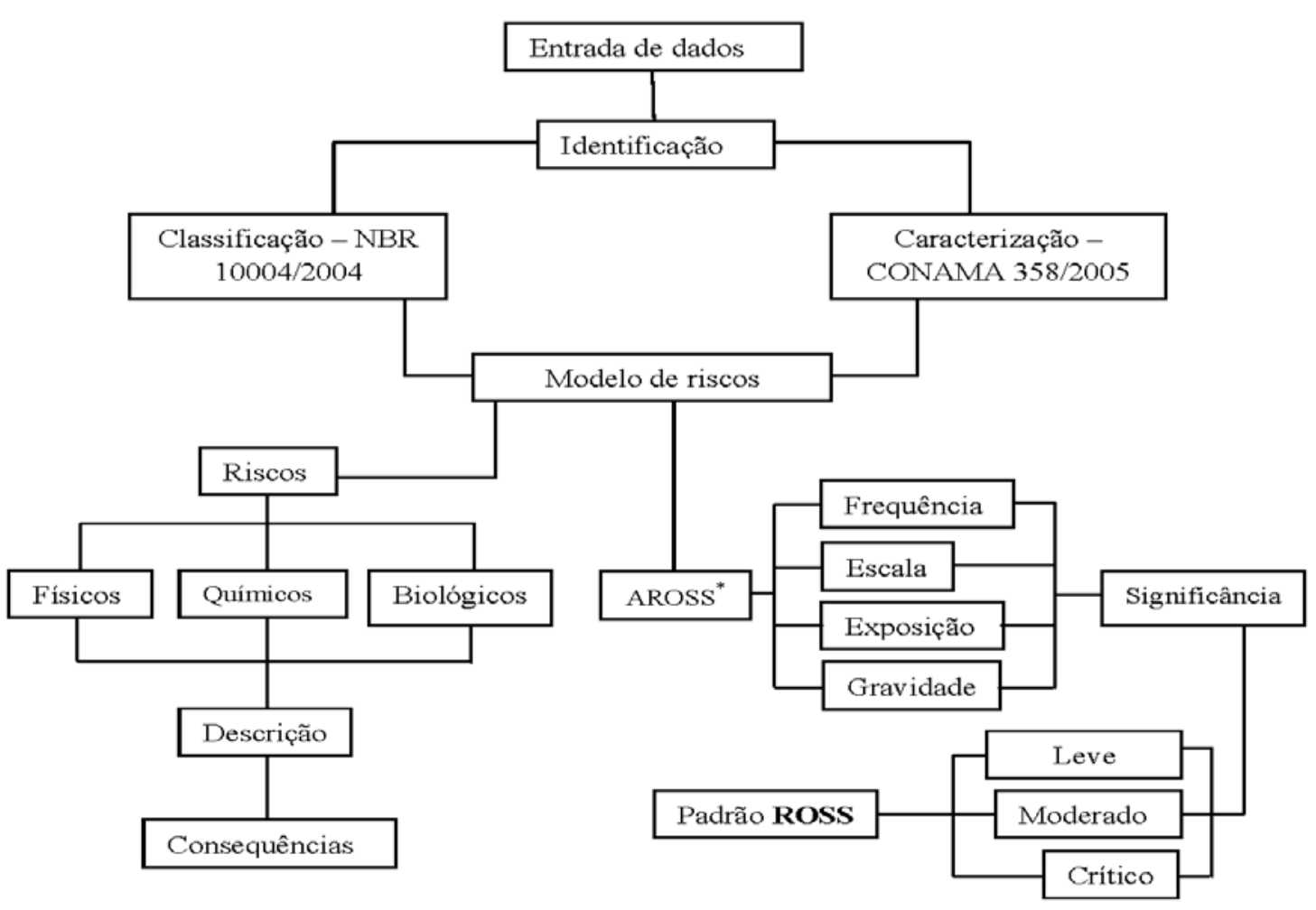

Figura 2. Fluxograma operacional do modelo para avaliação de riscos ocupacionais (padrão ROSS) para empresa de beneficiamento de resíduos sólidos urbanos. 
A escala determinada, e matematicamente adequada aos critérios selecionados, demonstra que através desse valor obtido, pode-se classificar os riscos à saúde e segurança ocupacional levantados, em três grupos (Cerqueira, 2006):

- $\quad$ Leves $\rightarrow 01 \leq \mathbf{R S}<30$

- Moderados $\rightarrow 30 \leq \mathbf{R S}<45$

- Críticos $\rightarrow \mathbf{R S} \geq 45$

\section{Padrão ROSS - Riscos ocupacionais à saúde e segurança \\ 0 estabelecimento do padrão} ROSS (riscos ocupacionais à segurança e saúde) objetiva ampliar o controle de qualidade para o trabalho com os resíduos sólidos urbanos, mediante $\mathrm{o}$ qual será possível ajustes e precauções para mitigar e atenuar riscos detectados para determinadas operações com materiais de interesse. A determinação do padrão ROSS segue o seguinte fluxograma, expresso na Figura 2.

Após classificação para os possíveis riscos, devidamente quantificados e identificados para um determinado setor produtivo e suas respectivas operações, o padrão ROSS estabelece margem para os riscos já classificados, em escala de significância, e implica em um padrão descritivo para condições de atividades executadas para um determinado setor produtivo e operações, como sendo executáveis (Padrão ROSS) ou não executáveis (fora do Padrão ROSS). Caso o Padrão ROSS não seja concebido a uma determinada atividade e/ou setor produtivo, faz-se necessário a proposição de ações, sobre as atividades que expressarem possibilidade para riscos moderados e críticos iminentes, através de medidas preventivas/intervencionista para determinada atividade. A totalização de riscos expressos mediante execução da matriz, deverá ser confrontada com os intervalos percentuais estabelecidos pelo padrão ROSS.

$$
\text { Padrão ROSS: } \text { Riscos = L (80-90\%) + M (10-15\%) + C (0-5\%) }
$$

\section{Resultados e discussão}

0 conjunto de resultados referentes à caracterização dos resíduos sólidos urbanos, de interesse para os catadores de materiais recicláveis da ARENSA, está apresentado na Tabela 2 que sistematiza os 16 tipos de materiais identificados no trabalho de triagem fidelizando a nomenclatura adotada pelos trabalhadores associados, juntamente com a identificação de exemplares.

Os riscos físicos e químicos, forma devidamente descritos por Batista et al. (2013), onde foi constatado que plásticos tipo grades e plásticos PVC expunham riscos físicos para situações de cortes e perfurações. Plásticos PEAD, caracterizados, principalmente, por embalagens de produtos de limpeza exalavam vapores dos conteúdos residuais, a exemplo do hipoclorito de sódio ou cálcio, ocasionando conjuntivites. Exemplares de produtos agrupados alumínios finos e alumínios duros, apresentaram a possibilidade de lesões, devido a riscos físicos em situações de perfuração e/ou cortes. Riscos físicos na ordem de perfurantes e cortantes, também foram ratificados no trabalho com a segregação de ferragens e extração das bobinas de cobre. Triagem de vidros reservou atenção para possibilidade de riscos de ordem física e química. 
Tabela 2. Descrição e terminologia dos Resíduos sólidos urbanos (RSU) identificados no trabalho dos catadores de materiais recicláveis da ARENSA, Campina Grande Paraíba.

\begin{tabular}{ll}
\hline RSU & \multicolumn{1}{c}{ Representação geral dos resíduos sólidos urbanos } \\
\hline Papel Papelão & Caixas de embalagens \\
Papel branco & Cadernos, livros, relatórios bancários e de órgãos públicos, apostilados \\
Papel misto & Panfletos, revistas, cartazes e quaisquer outras papéis pigmentados \\
Plástico PET & $\begin{array}{l}\text { Garrafas PET (Politereftalato de etileno) de refrigerantes, produtos de } \\
\text { higiene doméstica }\end{array}$ \\
Plástico grade & Cadeiras, mesas (Poliestireno - plástico rígido e resistente a impactos) \\
Plástico PEAD & $\begin{array}{l}\text { Recipientes de produtos de limpeza, iogurtes (Polietileno de alta densidade } \\
\text { - inquebrável, resistente a baixas temperaturas, leve, impermeável) }\end{array}$ \\
Plástico bacia & $\begin{array}{l}\text { Baldes de manteigas, tintas, diluentes e solventes químicos, utensílios } \\
\text { plásticos domésticos (PEAD) }\end{array}$ \\
Plástico carinas & $\begin{array}{l}\text { Calçados, mangueiras, correias de borracha e plásticas, brinquedos (PVC, } \\
\text { PEAD, EVA) }\end{array}$ \\
Plástico fino & Embalagens sem pigmentação, plásticos transparentes \\
Plástico PVC & Canos de construção civil (Policloreto de vinila) \\
Alumínio fino & Latinhas de diversas bebidas \\
Alumínio duro & Panelas, chaparias, grades e prateleiras \\
Longa Vida & Caixas de alimentos, laticínios (papel, papelão, polietileno e alumínio) \\
Vidros & Garrafas de bebidas, condimentados, recipientes de alimentos em conserva \\
Ferragens & Metais de várias origens, canos, grades, fogões, chaparias, hidrômetros, \\
Bobinado do cobre & Babulas de botijão de gás \\
& ventiladores dubos de TV, liquidificador, secador de cabelo, rádios, \\
\hline
\end{tabular}

Todos os grupos de resíduos sólidos urbanos, de interesse para os catadores de materiais recicláveis da ARENSA, apresentaram padrão de contaminação por procariotas do tipo Coliformes Termotolerantes, em escala de risco biológico, o que qualificou os grupos de materiais, triados e acondicionados pelos associados da ARENSA, como potenciais para riscos biológicos, em comprometimentos à saúde dos trabalhadores. Foi notada como fonte contaminadora dos materiais recicláveis a presença de resíduos orgânicos, representados por restos de alimentos dentro de recipientes, como também dispersos, e de resíduos de origem sanitária.

A elaboração da matriz de riscos para os resíduos sólidos urbanos, relacionados às atividades executadas para triagem e acondicionamento satisfatórios, como também aos riscos ocupacionais identificados nos trabalhos com esses materiais, propiciou a classificação dos riscos evidenciados a partir do resultado de significância calculado a partir das varáveis de composição da matriz. 
Tabela 3. Matriz de Avaliação de Riscos à Segurança e Saúde Ocupacional para o trabalho com resíduos sólidos urbanos (RSU). Padrão de cores para os riscos ocupacionais de acordo com a NR9/2011 (Programa de prevenção de riscos ambientais). Padrão de cores para classificação de risco NR-26/2011 (Sinalização de Segurança).

\begin{tabular}{|c|c|c|c|c|c|c|c|c|c|}
\hline \multicolumn{4}{|l|}{ Matriz de Riscos Ocupacionais } & \multicolumn{4}{|c|}{$\begin{array}{c}\text { Avaliação do risco à saúde e segurança } \\
\text { ocupacional - ARSSO }\end{array}$} & \multirow{9}{*}{ 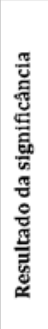 } & \multirow{9}{*}{ 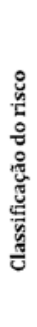 } \\
\hline Frequência de risco: 1 Improváve & rovável; & el; 4 Muito & & \multirow{8}{*}{ 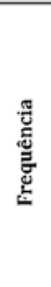 } & \multirow{8}{*}{ 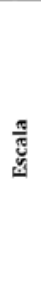 } & \multirow{8}{*}{ 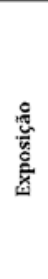 } & \multirow{8}{*}{$\begin{array}{l}\frac{0}{\pi} \\
\frac{\pi}{\pi} \\
\text { ș } \\
\text { s. }\end{array}$} & & \\
\hline $\begin{array}{l}\text { Escala: } 1 \text { Até } 30 \% \text { dos Trabalhador } \\
5 \text { Mais de } 70 \% \text { dos Trabalhadores }\end{array}$ & $30 \%$ e 7 & Trabalhador & & & & & & & \\
\hline $\begin{array}{l}\text { Exposição: } 1 \text { Até } 25 \% \text { da Jornada c c } \\
\text { a } 75 \% \text { da jornada de Trabalho }\end{array}$ & 3 Entre & $5 \%$ da Jorn & alho; 5 Superior & & & & & & \\
\hline Gravidade: 1 Efeitos leves; 3 Efeito & as; 5 Efeit & & & & & & & & \\
\hline Resultado da significância: $R S=$ & $\mathbf{x}$ (VEscal. & osição + VC & & & & & & & \\
\hline Classificação do risco: Leve $\rightarrow 01$ & Moderado & $\leq \mathbf{R S}<45 \mathrm{e}$ & $\mathbf{R S} \geq 45$ & & & & & & \\
\hline \multirow{2}{*}{ Resíduos sólidos urbanos } & \multicolumn{3}{|c|}{ Riscos } & & & & & & \\
\hline & Físico & Químico & Biológico & & & & & & \\
\hline Papel Papelão & & & 0 & 3 & 5 & 5 & 1 & 33 & M \\
\hline Papel branco & O & & & 3 & 5 & 3 & 3 & 33 & M \\
\hline Papel misto & & & & 1 & 5 & 3 & 1 & 9 & L \\
\hline Plástico PET & & & 0 & 2 & 5 & 5 & 1 & 22 & $\mathbf{L}$ \\
\hline Plástico grade & O & & & 3 & 3 & 3 & 3 & 27 & $\mathbf{L}$ \\
\hline Plástico PEAD & & & & 3 & 5 & 5 & 3 & 39 & M \\
\hline Plástico bacia & O & 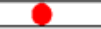 & O & 2 & 3 & 5 & 5 & 26 & L \\
\hline Plástico carina & & & & 1 & 5 & 3 & 1 & 9 & $\mathbf{L}$ \\
\hline Plástico fino & & & & 1 & 5 & 3 & 1 & 9 & L \\
\hline Plástico PVC & 0 & & () & 4 & 3 & 3 & 5 & 44 & M \\
\hline Alumínio fino & C & & 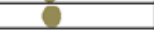 & 4 & 3 & 3 & 5 & 44 & $M$ \\
\hline Alumínio duro & 0 & & 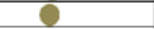 & 3 & 5 & 3 & 5 & 39 & M \\
\hline Longa Vida & & & & 1 & 5 & 3 & 1 & 9 & D \\
\hline Vidros & 0 & 0 & 0 & 4 & 5 & 3 & 5 & 52 & C \\
\hline Ferragens & 0 & & 0 & 4 & 3 & 5 & 5 & 52 & $\mathrm{C}$ \\
\hline Bobinado do cobre & 8 & & & 4 & 1 & 3 & 5 & 36 & M \\
\hline
\end{tabular}

Classificação dos riscos: Leve (L); Moderado (M) e Crítico (C).

A determinação da frequência de risco foi baseada na possibilidade da ocorrência de acidentes, para riscos físicos e químicos, e contaminação para risco biológico. 0 acompanhamento foi baseado na observação direta e minuciosa da execução do trabalho dos catadores de materiais recicláveis com os diferentes tipos de resíduos, chegando a julgamentos para todos os tipos identificados. Para a variável escala, considerou-se a quantidade, no universo amostral de seis trabalhadores, quantos estavam envolvidos diretamente com a triagem e/ou acondicionamento de determinado resíduo.

A avaliação da frequência dos riscos apresentou como resultados riscos improváveis para o trabalho com papel misto, plástico fino, plástico carina e embalagens longa vida, os quais apenas requisitarem o manuseio após a triagem para sacos de reservação. Riscos pouco prováveis foram determinados no trabalho com plástico PET e plástico tipo bacia, referentes ao manuseio simplificado dos materiais, porém, as condições sanitárias dos resíduos resguardaram atenção quanto o aspecto higiênico dos invólucros mediante intervenção sem a utilização de luvas. A determinação de riscos prováveis foi concedida a resíduos que exigiram trabalho de redução dos produtos, o que aumento o tempo de contato dos trabalhadores com os mesmo, durante o processo de triagem, podendo ocasionar riscos físicos e químicos, como identificado para papel papelão, papel branco, plástico grade, plástico PEAD e alumínio duro. A determinação de riscos com frequência de ocorrência muito provável foi determinada para atividade que exigiram emprego de força física e/ou ferramentas para intervenção de redução sobre os resíduos, objetivando redução de volume para acondicionamento. Os grupos caracterizados como de riscos muito frequentes foram plástico PVC, alumínio fino, vidros, ferragens e obtenção das bobinas de cobre. Vale salientar que condições sanitárias indevidas foram observadas em todos os grupos de 
resíduos, com exceção da bobina de cobre.

A escala de envolvimento dos catadores de materiais recicláveis, após a devida averiguação, possibilitou a descrição de que até $30 \%$ dos associados trabalham com a extração das bobinas de cobre, visto esta atividade operacional requisitar dedicação exclusiva e uso de ferramentas (marretas, chaves de fenda e alicates), sendo executada apenas por um trabalhador da ARENSA durante $o$ expediente acompanhado; entre 3 e 4 trabalhadores associados, equivalente a margem de $30 \%$ a $70 \%$ do total, triaram e acondicionaram plástico grade, PVC, ferragens e alumínio fino, mediante a redução dos materiais e mais de $70 \%$ destes realizam triagem $\mathrm{e}$ acondicionamento de papel (papelão, branco e misto), plástico (PET, PEAD, carina e fino), alumínio duro, embalagens longa vida e vidro, onde materiais relacionados são colocados sobre a mesa de triagem para conseguinte desenvolvimento do trabalho.

Quanto ao tempo de exposição referente ao expediente vespertino desenvolvido pelos catadores de materiais recicláveis da ARENSA, destina-se de $25 \%$ a $75 \%$ da jornada de trabalho para tarefas com papel (branco e misto), plástico (grade, carina, PVC e fino), alumínio (fino e duro), embalagens longa vida, vidros e extração das bobinas de cobre. Já os produtos triados e acondicionados, em período parcialmente integral, ou seja, por mais de $75 \%$ da jornada de trabalho, são papel papelão, plástico (PET, PEAD e bacia) e ferragens.

Os riscos são caracterizados, de acordo com Berkenbrock e Bassani (2010), com elevada probabilidade de ocorrência e a severidade para os trabalhadores envolvidos, seja por ocasionar acidentes com lesões e/ou contaminações representativos. Com advento desse raciocínio, a gravidade para riscos de efeito leve foi determinada para papel (papelão e misto), plástico (PET, carina e fino) e embalagens longa vida, mediante os listados apenas requisitarem a triagem e acondicionamento sem necessidade de intervenções outras sobre a estrutura física dos materiais. Lesões de gravidade moderada foram emblemadas para papel branco, plástico grade e plástico PEAD, visto intervenção sobre estes com o emprego direto das mãos para propiciar redução de volumes. Os riscos designados de alta gravidade se referiram a plástico (bacia e PVC), alumínio (duro e fino), vidros, ferragens e extração de bobinas de cobre. Atividades com tais materiais exigem forte intervenção para redução de volume para acondicionamento.

Após as devidas verificações e levantamento de variáveis para matriz de riscos, foi procedida a análise de significância e concomitante classificação dos riscos em escala de periculosidade, de acordo com a Norma Regulamentadora, MTE NR-26/2011, a qual dispõe sobre prevenção de acidentes, indicação de equipamentos de segurança e delimitação de áreas para fins de canalização de substâncias perniciosas à vida. Como resultado, obteve-se para riscos leves as atividades com papel misto, plástico (PET, grade, bacia, carina e fino) e embalagens longa vida. Riscos moderados resultaram das atividades com papel (papelão e branco), plástico (PEAD e PVC), alumínio (duro e fino) e extração de bobinas de cobre. Riscos críticos foram apontados para as atividades desenvolvidas com vidros e ferragens.

A aplicação do padrão ROSS (Riscos Ocupacionais à Saúde e Segurança) é pertinente à obtenção de dados referentes ao nível de possibilidades para ocorrências de situações danosas em escala idealizada de acordo com o conceito de empresa ideal, apresentado anteriormente na apresentação metodológica. Sendo assim, o padrão ROSS tende a ser concedido ao grupo operacional que se enquadra nas faixas estabelecidas para cada nível de riscos. Na Tabela 4 são apresentados 
resultados percentuais dos riscos ocupacionais oriundos da matriz de riscos aplicada, e confronto com as faixas de permissividade do padrão ROSS.

Tabela 4. Aplicação do padrão ROSS de acordo com resultados de significância e classificação da matriz de riscos.

\begin{tabular}{|l|c|c|}
\hline Resultado de significância & Padrão ROSS & Resultados da matriz \\
\hline Leve & $\mathbf{8 0 - 9 0 \%}$ & $43,75 \%$ \\
\hline Moderado & $10-15 \%$ & $43,75 \%$ \\
\hline Crítico & $0-5 \%$ & $12,5 \%$ \\
\hline
\end{tabular}

Aplicado o padrão ROSS, foi possível constatar que as atividades executadas pelos catadores de materiais recicláveis da ARENSA, junto aos 16 diferentes produtos identificados e caracterizados quanto aos riscos ocupacionais, apresentou referenciais quantitativos para classificação dos riscos superiores aos valores estabelecidos, não sendo possível a concessão do padrão ROSS a qualquer atividade desempenhada.

\section{Conclusão}

As condições insalubres do galpão de triagem da ARENSA sinalizam para condições emergentes de cuidados sanitários e à saúde, visto ausência de ambiente para realização de refeições, higiene pessoal e higiene dos resíduos sólidos urbanos, quando necessário. 0 não emprego de equipamentos de proteção individual (EPI's) constitui cenário agravante para as atividades exercidas com diferentes materiais de interesse, potencializando riscos de comprometimento à saúde e segurança.

A proposição da matriz de riscos possibilitou a qualificação dos diferentes resíduos e suas atividades mediante a estimativa de significância, por composição de variáveis para acompanhamento dos trabalhos desenvolvidos pelos catadores de materiais recicláveis e classificação dos riscos em nível de gravidade. Realizadas as prerrogativas, estas foram confrontadas com os limites estabelecidos pelo padrão ROSS (riscos ocupacionais à saúde e segurança), em avaliação de enquadramento nas faixas idealizadas para a graduação dos riscos. Riscos desprezíveis foram apontados no trabalho desenvolvido com papel misto, plásticos (PET, grade, bacia, carina e fino) e embalagens longa vida, perfazendo $43,75 \%$ do total do materiais. Riscos moderados foram determinados para atividades com papéis (papelão e branco), plásticos (PEAD e PVC), alumínios (fino e duro) e para a obtenção das bobinas de cobre, representando $43,75 \%$. Riscos críticos foram constados nos trabalhos desenvolvidos com vidros e ferragens, que junto ao total de resíduos representou 12,5\%. Após equiparação junto às faixas determinadas pelo padrão ROSS, verificou-se que os riscos identificados estavam acima dos determinados para operações ideias para a integridade e seguridade dos catadores de materiais recicláveis, fazendo-se necessário a tomada de decisões para aperfeiçoamento, identificação dos riscos potenciais ofertados pelos diferentes materiais e utilização de equipamento para mitigação de situações que preconizam acidentes e comprometimento à saúde. 


\section{Conflito de interesses}

de interesses.

O autor declara não haver conflito

\section{Referências}

ABNT - Associação Brasileira de Normas Técnicas. ABNT NBR 10.004:2004 Resíduos sólidos: Classificação. Rio de Janeiro: ABNT, 2004.

Andrade, R. M.; Ferreira, J. A. A gestão de resíduos sólidos urbanos no Brasil frente às questões da globalização. REDE - Revista Eletrônica do Prodema, v. 6, n. 1, p. 7-22, 2011. Disponível em: <http://www. revistarede.ufc.br/rede/article/view/118>.

Acesso em: 18 out. 2018.

Batista, F. G. A.; Lima, V. L. A.; Silva, M. M. P. Avaliação de riscos físicos e químicos no trabalho de catadores de materiais recicláveis - Campina Grande, Paraíba. Revista Verde de Agroecologia e Desenvolvimento Sustentável, v. 8, n. 2, p. 284-290, 2013.

Berkenbrock, P. E.; Bassani, I. A. Gestão do risco ocupacional: uma ferramenta em favor das organizações e dos colaboradores. Revista Interdisciplinar Científica Aplicada, v. 4, n. 1, p. 43-56, 2010.

Brasil. Portaria MT no 25, de 29 de dezembro de 2011. NR 09. Programa de prevenção de riscos ambientais. Brasília: MTE, 2011.

Brasil. Portaria MT no 229, de 24 de maio de 2011. Altera a Norma Regulamentadora n. -26 . Disponível em: <https://sogi8.sogi. com.br/Arquivo/Modulo113.MRID109/Regis tro36491/portaria sit no 229, de 24-052011.pdf>. Acesso em: 18 out. 2018.

Brasil. Resolução CONAMA no 357, de 17 de março de 2005. Dispõe sobre a classificação dos corpos de água e diretrizes ambientais para o seu enquadramento, bem como estabelece as condições e padrões de lançamento de efluentes, e dá outras providências. Disponível em: <http://www2. mma.gov.br/port/conama/legiabre.cfm?codl egi=459 . . Acesso em: 18 out. 2018.
Brasil. Resolução CONAMA no 358, de 29 de abril de 2005. Dispõe sobre o tratamento e a disposição final dos resíduos dos serviços de saúde e dá outras providências. Disponível em: <http://www2.mma.gov.br/port/ conama/legiabre.cfm?codlegi $=462>$. Acesso em: 18 out. 2018 .

Brasil. Lei no 12.305, de 2 de agosto de 2010. Institui a Política Nacional de Resíduos Sólidos; altera a Lei $\mathrm{n}$ o 9.605, de 12 de fevereiro de 1998; e dá outras providências. Disponível em: <http://www.planalto. gov.br/ccivil_03/_ato2007-2010/2010/lei/ 112305.htm>. Acesso em: 20 nov. 2018.

BSI. OHSAS 18001: Especificação para sistemas de gestão de saúde ocupacional e segurança, Reino Unido. Disponível em: <https://www.bsigroup.com/en-GB/ohsas18001-occupational-health-and-safety/>. Acesso em: 18 out. 2018.

Cerqueira, J.P. Sistemas de gestão integrados: ISO 9001, NBR 16001, OHSAS 18001, SA 8000: Conceitos e aplicações. Rio de Janeiro: Qualitymark, 2006.

Cicco, F. A OHSAS 18001 e a certificação de sistemas de gestão da segurança e saúde no trabalho. São Paulo: QSP, 2009. Disponível em: <http://www.qsp.org.br/ artigo.shtml>. Acesso em: 24 out. 2018.

ISO - International Organization for Standardization. ISO 45001:2018 Occupational health and safety management systems - Requirements with guidance for use. Genebra: ISO, 2018. Disponível em: <https://www.iso.org/obp/ ui/\#iso:std:iso:45001:ed-1:v1:en>. Acesso em: 24 out. 2018 .

Jacobi, P. Educação ambiental, cidadania e sustentabilidade. Cadernos de Pesquisa, n. 118, p. 189-205, 2003. https://doi.org/ 10.1590/S0100-15742003000100008

Torres, V. F. N.; Gama, C. D. Engenharia ambiental subterrânea e aplicações. Rio de Janeiro: CETEM/CYTED, 2005. Disponível em: <http://mineralis.cetem.gov.br/handle/ cetem/677>. Acesso em: 24 out. 2018. 
Vieira, A. C. M.; Silva, E. W. F.; Coutinho, R. K. S.; Ramos, S. J. Análise da política nacional de resíduos sólidos, no gerenciamento de resíduos sólidos urbanos domiciliares no Município de Pindamonhangaba. Anais do IX SEGet - Simpósio de Excelência em Gestão e Tecnologia, Resende, 2012.

(CC) Informação da Licença: Este é um artigo Open Access distribuído sob os termos da Licença Creative Commons Attribution, que permite uso irrestrito, distribuição e reprodução em qualquer meio, desde que a obra original seja devidamente citada. 